\title{
Assessment of Craniofacial Morphology in Mouth Breathing Children A retrospective case-control study
}

\author{
DAVID ANGELESCU ${ }^{1}$, TEODORA ANGELESCU르, MEDA ROMANA SIMU ${ }^{1 *}$, ALEXANDRINA MUNTEAN ${ }^{1}$, ANCA STEFANIA MESAROS ${ }^{3}$, \\ SORIN BERBECE4, SILVIU ALB ${ }^{5}$ \\ ${ }^{1}$ Iuliu Hatieganu University of Medicine and Pharmacy, Department of Pedodontics, 8 Victor Babes Str., 400012, Cluj Napoca \\ Romania \\ IIuliu Hatieganu University of Medicine and Pharmacy, Department of Oral and Maxillo-Facial Surgery, 8 Victor Babes Str., 400012, \\ Cluj Napoca Romania \\ ${ }^{3}$ Iuliu Hatieganu University of Medicine and Pharmacy, Department of Dental Propedeutics and Esthetics, 8 Victor Babes Str., \\ 400012, Cluj Napoca Romania \\ ${ }^{4}$ Dunarea de J0s, University, Faculty of Medicine and Pharmacy, Department of Morphological and Functional Sciences, \\ 47 Domneasca Str., 800008, Galati, Romania \\ ${ }^{5}$ Iuliu Hatieganu University of Medicine and Pharmacy, Department of Cervico-Facial Surgery and ENT, 8 Victor Babes Str., 400012, \\ Cluj Napoca Romania
}

\begin{abstract}
The aim of this retrospective case-control study is to determine a possible correlation between breathing mode and craniofacial morphology. The study was carried out in the Department of Pedodontics, Iuliu Hatieganu University of Medicine and Pharmacy, Cluj-Napoca, Romania. The sample comprised 80 patients, age between 6 and 13 years, which were divided in two groups based on respiratory pattern: control group composed of 38 nasal breathing children and case group composed of 42 oral breathing children. Three quantitative craniofacial parameters were measured from the frontal and lateral photos: facial index, lower facial height ratio and upper lip ratio. The statistical analysis showed a significant higher facial index $\left(p=0.006^{*}\right)$ and an increase lower facial height $\left(p=0.033^{*}\right)$ for the oral breathers group. No differences in facial morphology were found between genders and age groups, when comparing the data between the same type of respiratory pattern children. Spearman's rho Correlation show a significant positive correlation $\left(p=0.002^{*}\right)$ between facial index and lower facial height and a significant negative correlation between facial index and upper lip $(p=0,005 *)$. Long faces children are more likely to develop oral breathing in certain conditions, which subsequently have a negative effect on increasing the lower facial height by altering the postural behavior of mandible and tongue.
\end{abstract}

Keywords: craniofacial morphology, facial growth, facial index, long face, oral breathing.

The relationship between respiration and craniofacial growth has been debated for manyyears [1]. According to the initial Moss's Functional Matrix Theory the growth and development of viscerocranium is primary influence by extrinsic factors like breathing, mastication and swallowing (epigenetic factors) [2-4]. As a consequence, any breathing disorders in growing patients left untreated for a long period of time have a negative effect on craniofacial morphology. On the other hand, other authors advocate the idea of genomic supremacy over the processes involve in face development, with little or no influence of extrinsic factor in this process. [5]. The resolution of this controversy can only be based on the strength of evidence offered by well designed clinical studies, which so far seems to have divergent ideas regarding this issue $[1,6,7]$.

Oral breathing may result in most of the cases from an increase upper airway resistance or from habit. Any kind of obstructive mechanisms, such as adenotonsillar hypertrophy, allergic rhinitis or septal deviation may trigger the formation of a new pathological pathw ay for the air to get to the lungs $[3,4,7-9]$. In a five years follow up study, Linder and Aronson found that after removing the obstructive enlarged adenoid tissue, the children exhibita normal growth development similar to the control group [10-13]. This is valid if the surgery is followed up by a functional shift from oral to nasal breathing, butthis doesn't happen all the time, as oral breathing may persist even though there is no upper airway resistance [15].
The long face syndrome often referred as adenoid face is a clinical sign used in pediatric medicine to describe a person who is suffering from breathing problems which may affect his morphological and psychological development [14]. Mouth breathers are defined as those persons with predominantly vertical face growth, weak mandibular elevator muscles, lip incompetence, narrow alar base, steep mandibular plane angle and retrognathic mandible, compared with faces of healthy controls $[1,4,14]$. It is also typical for these patients to have an extended head posture and a forward inclined upper cervical spine [16,17].

The main purpose of the treatment is focused on clearing the upper airway from any obstruction phenomena. Both surgical and medical treatments continue to be performed to modify respiration pattern in order to improve facial growth [11-13]. However, there is no clear evidence between the causal relationship of oral breathing and facial growth, nor that different treatment modalities can actually modify the respiratory mode $[1,6]$.

The aim of this study is to determine a possible correlation between breathing mode and craniofacial morphology, consider as the null hypothesis $(\mathrm{HO})$ the statement that there is no difference regarding craniofacial morphology between oral breathers and nasal breathers and also it is no gender dependent.

Therefore, the following questions should be answered in this study:

\footnotetext{
*email: romana.simu@umfcluj.ro; Phone: : +40-264-597-256 All the authors had equal scientific contribution in publishing this material.
} 
Can we predict the type of breathing in a growing patient using facial characteristics?

Is there a correlation between respiratory mode and long faces subjects?

Is oral breathing a factor risk for an increase lower facial height?

\section{Experimental part}

This is a retrospective, observational case-control study carried out from January 2015 to September 2016. The study was approved by the Ethics Committee of Iuliu Hatieganu University of Medicine and Pharmacy, ClujNapoca, protocol number 314. All parents or legal guardians signed a written consent form and all children agreed to take part in the study. The sample comprised 80 patients, $42(52.5 \%)$ boys and $38(47.5 \%)$ girls with age between 6 and 13 years old. The mean age of the sample was 9.78 , with the SD of 1.82 (Table 1 ).

All the subjects enrolled in this clinical study were selected among the orthodontic patients treated in the department of Orthodontics and Pediatric Dentistry, ClujNapoca and private dental offices. Using G-P*Power program for effect size $d=0.8$, risk level $\alpha=0.05$ and for power $1-\beta=0.80$ we got that the representativeness (Figure 1) is given by $26 / 26$ for boys and girls. So, we conclude that our samples are representative.

The inclusion criteria of the study were:

-Age between 6 and 13 years

-Caucasian, to avoid racial interference

-General good health following airway pathologies: enlarged adenoid tissue, tonsil hyperplasia, turbinate hyperplasia, deviated nasal septum or allergic rhinitis.

The exclusion criteria were:

-Craniofacial malformations

-Orthodontic treatment, facial surgery or speech therapy before the study

-Facial trauma
-Obstruction of upper airways due to at least one of the

The sample was divided in two groups based on respiratory pattern. The control group consisted of 38 $(47.5 \%)$ nasal breathing children and case group of 42 (52.5\%) oral breathing children. In order to compare the data between younger and older patients, we have divided the patients in two age groups: one between 6-9 years $(n=35)$ and the other between $10-13(n=45)$ years.

\section{Breathing mode evaluation}

The evaluation of breathing pattern was done by analyzing the data taken from questionnaires completed by the parents or legal representatives of children and from the clinical examination of patients. The data collected from the questionnaires focus on medical history and type of breathing (daytime/nighttime mouth breathing, snoring etc.). The clinical examination assessed: the lips position at rest and the facial muscular tonus with closed and open lips. In the cases where we found the lip position at rest closed, but the data collected from the questionnaires was in favor for oral breathing, we have decided to include those patients in case group. The rationale of this decision resides in the fact that mouth breathing can coexist with a decrease nasal resistance and normal muscular balance [1].

\section{Facial type evaluation}

The evaluation of facial parameters was made on the frontal and lateral photos using Adobe Acrobat Reader DC measuring tool, after converting the jpeg files into a pdf file format using Preview Program from Mac OS Sierra. The photos were taken with a digital camera positioned 1.5 meters away from the patients in standing position. The children were asked to keep their usual body posture with eyes open glancing to the horizon line.

The assessment of facial characteristics comprised three vertical ratio measurements: facial index, lower facial height and upper lip. We have decided to use ratios to avoid anykind of magnification errors, which might appear during photo acquisition if the distance between the digital camera and the subjects was not perfectly respected. The

\begin{tabular}{|l|l|l|l|l|} 
& $\begin{array}{l}\text { Age } \\
\mathrm{n}=80\end{array}$ & $\begin{array}{l}\text { Facial Index } \\
\mathrm{n}=80\end{array}$ & $\begin{array}{l}\text { Lower Facial } \\
\text { Height } \mathrm{n}=80\end{array}$ & $\begin{array}{l}\text { Upper } \\
\text { Lip }\end{array}$ \\
\hline Mean & 9.78 & 89.4728 & 50.7182 & 33.1356 \\
\hline Std. Deviation & 1.821 & 5.79862 & 2.99305 & 2.71189 \\
\hline Minimum & 6 & 80.37 & 45.00 & 26.06 \\
\hline Maximum & 13 & 102.63 & 58.89 & 39.55 \\
\hline
\end{tabular}

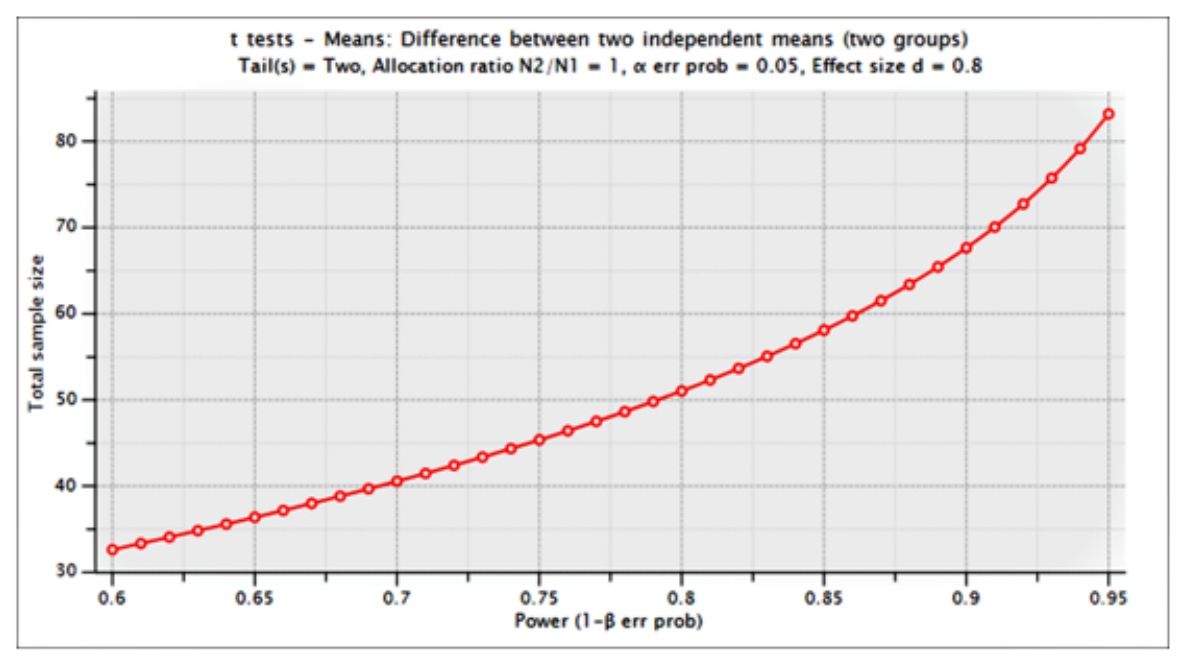

Fig. 1. Sample size for different values of power (1-ß) 
quantitative variables that we used for the statistical analysis represented the mean between the same measurements taken from the frontal and lateral photos.

The data collected included the following measurements:

-facial height, measured from soft tissue nasion (the concave or retruded point in the tissue overlying the area of the frontonasal suture) to soft tissue gnathion (the midpoint between the most anterior and inferior points of the soft tissue chin in the midsagittal plane).

-facial width, the distance between the two zygion points (the most lateral point of each zygomatic arch).

-upper facial height, measured from ophryon (the most prominent midline point between the eyebrows) to subnasion (deepest point of the nasolabial angle).

-lower facial height, the distance between subnasion and soft tissue point gnathion.

-upper lip height, measured between subnasion and the lowermost point on lower border of the upper lip.

Facial index was determined by calculating the ratio of the facial height to the width of the face multiplied by 100 .

The lower facial height ratio was determined by dividing the lower facial height to the sum of lower and upper facial height multiplied by 100 .

The upper lip ratio was determined by dividing the length of the upper lip to the lower facial height multiplied by 100 .

Five different facial types were classified using the facial index number as follow: up to 78.9 hypereuryprosopic; from 79.0 to 83.9 euryprosopic; from 84.0 to 87.9 mesoprosopic; from 88.0 to 92.9 leptoprosopic; above 93.0hyperleptoprosopic [24,25].

\section{Statistical methods}

Statistical analysis was performed using SPSS 24 for Mac. For all tests the significance level was set to $p<0.05$. Descriptive analysis was performed for all variables by calculating the mean, standard deviation, minimum and maximum values for quantitative characteristics.
Kolmogorov-Smirnov statistics were used for all quantitative variables to find if the data is normal distributed and Levene's Test for homogeneity of variance. We found that the data was normally distributed with equal variances between nasal-oral breathers, genders and age groups, except for the facial index (non-normality $p=0.046$ ) and the lower lip (unequal variance $p=0.018$ ) within respiratory type groups. As a consequence, group differences were analyzed with both one /two way ANOVA and MannWhitney test for nonparametric two independent samples.

Chi-square test for independence was used to assess the difference between different facial types, breathing mode and age groups of the sample.

Correlation analysis was used to assess the strength of the relationship between all three variables measured in this study. Spearman's rank correlation coefficient was used instead of Pearson's correlation, because of nonnormality in the facial index variable.

Progressive binary logistics was use to forecast the power of prediction of respiratory pattern using patient's facial measurements.

\section{Results and discussions}

The evaluation of facial morphology between respiratory types was done using both parametric and nonparametric tests, according to the results of Kolmogorov-Smirnov test for the normality of data. Statistically significant differences were found between nasal and oral breathers regarding facial index $\left(p=0.006^{*}\right)$ and lower facial height ratio $\left(p=0.033^{*}\right)$ (Figure 2a,b).

The upper lip was found to be shorter in oral breathing group, but the result is not statistically significant $(p=0.294)$ (Fig. 3a).

To assess the age related differences in craniofacial morphology, one way ANOVA was performed. The older group had a significantly higher facial index score compare with the younger one $\left(p=0.043^{*}\right)$ and also a short upper lip $(p=0.052)$. The lower facial height ratio was almost the
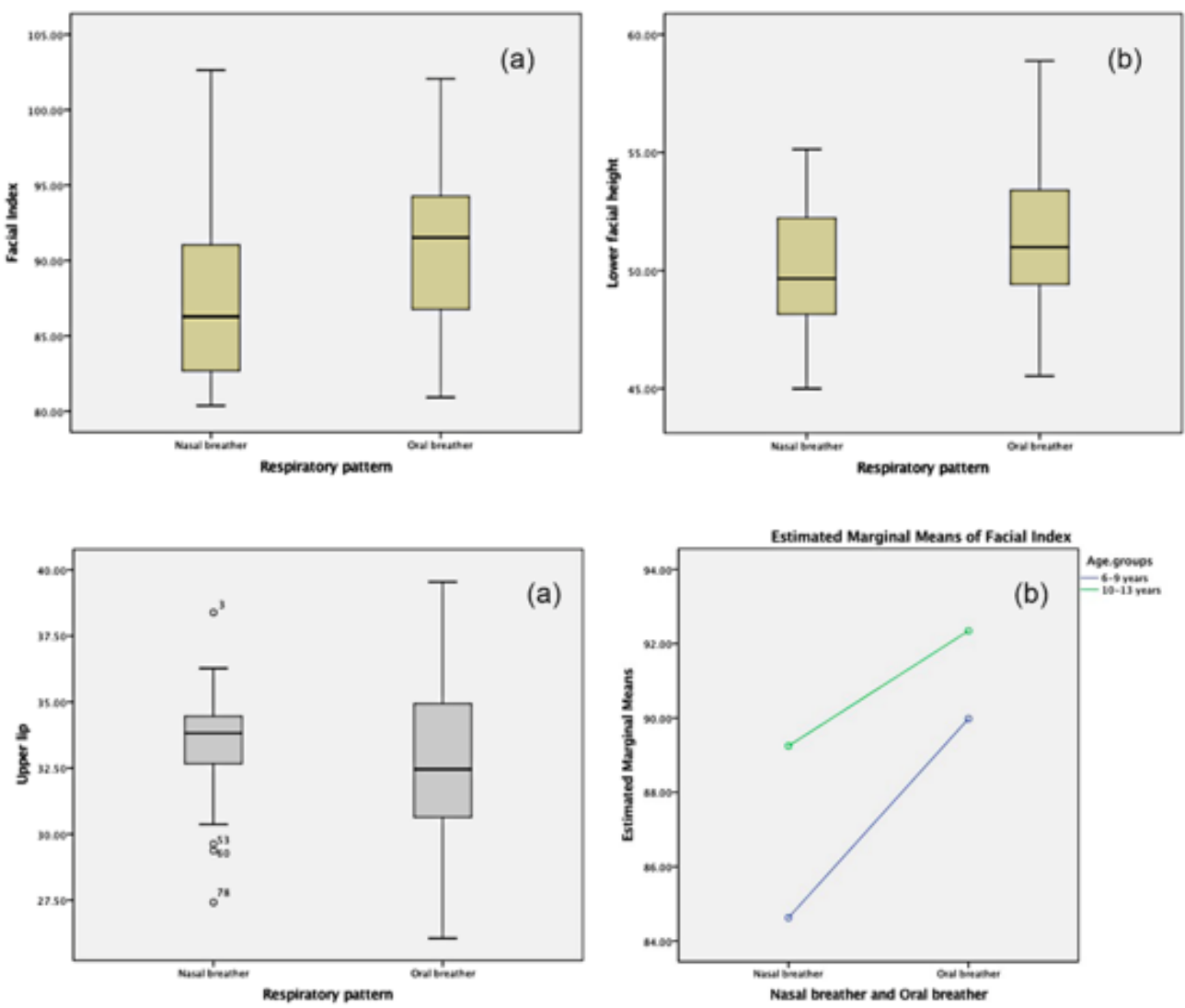

Fig. 3. (a) The upper lip is shorter on oral breathing group $(p=0.294$, One way ANOVA). (b) Two way

ANOVA shows no significant difference in facial index ratio $(p=0.363)$ in age related groups of different respiratory patterns. 
same between the two groups ( $p=0.544)$, but this type of analysis doesn't take in account which of the older and younger patients are nasal or oral breathers. As a consequence, two way ANOVA was performed in order to introduce the respiratory pattern together with age related groups in the independent variables. As Figure $3 b$ shows, we didn't find any age related differences between nasal and oral breathers, regarding facial index $(p=0.363)$. The same results were also found for the lower facial height ratio $(p=0.182)$ and upper lip ratio $(p=0.494)$.

We also tested for any gender differences in facial morphology, butall the results confirmed the null hypothesis which stated that: there is no difference between boys and girl regarding craniofacial morphology.

Three facial types were identified in our sample according to the selection criteria mention before. One way Anova was used to compare the differences between upper lip and lower facial height among this groups. The results demonstrate that the longer the face is, the shorter the upper lip $(p=0.015)$ and the longer lower facial height ratio are $(p=0.002)$. According to the Post Hoc Tests the significant differences were noticed between the hyperleptoprosopic faces and all the other two types of faces as Figure $4 a$ and $4 \mathrm{~b}$ illustrate.

For analyzing the differences between all four facial types found in our sample and respiratory pattern, Pearson Chi-Square test was used, which rejected the null hypothesis with a $p$ value of 0.028 . The alternative hypothesis was accepted, which states that there is a significant difference in breathing pattern between all three facial types (Table 2). The same test found no difference between genders $(p=0.382)$ and age groups $(p=0.102)$ regarding respiratory mode.

Although this study focused primarily on the difference between craniofacial characteristics of oral and nasal breathers, it was also of interest to examine if there is any association between facial index, lower facial height and upper lip ratio. The relationship between all these variables was assessed by using Spearman's rho Correlation. A significant positive correlation $(p=0.002)$ was found between facial index and lower facial height and a significant negative correlation between facial index and upper lip $(p=0.005)$. No correlation was found between upper lip and lower facial height ratio $(p=0.297)$.

The odds of predicting the respiratory pattern using the quantitative data gathered in this study has an overall percent of $67.5 \%$. This data was obtained by using progressive binary logistics to forecast the power of prediction of facial index, lower facial height and upper lip ratio on the respiratory mode of patients. None of these variables has a significant power in predicting the respiratory pattern, but between them, facial index has the higher odds $(p=0.058)$.

This study focused on evaluation of facial characteristics in mouth breathing children. In order to determine if an altered respiratory function is a risk factor in developing the adenoid face, we compare three facial quantitative variables of 42 oral breathing children to 38 nose breathing children. Our results support the findings of other articles in the literature, that there are major craniofacial differences between the two groups [17-23]. Breathing impaired subjects showed a significantly higher facial index and lower facial height ratio, than the controls. The argument for this change in facial morphology is based on a cascade of events, which had the starting point in altered respiratory function [18-19] The first and immediate effect is the perturbed neuromuscular balance, characterized by head extension, posterior rotation of mandible, lower and backward tongue position associated with unbalance buccinator pressure on the maxilla. If these changes are kept for a long period of time in a growing patient the consequences will be upon the developing skeletal system [11-13].

In an attempt to establish a causality theory for the genetic and environmental factors involved in craniofacial development, a prospective longitudinal study should be performed, butthis is hardly possible due to ethical reasons. Even though this is a retrospective study, we analyzed the facial index measurements for two different age groups (6-9 years and 10-13 years), in the presence or absence of the risk factor: oral breathing. The older group had a significantly dolichocephalic type of face compare with the younger one, and this supports the conclusion of Cheng and Enlow (1988) that the younger the subject is, the less
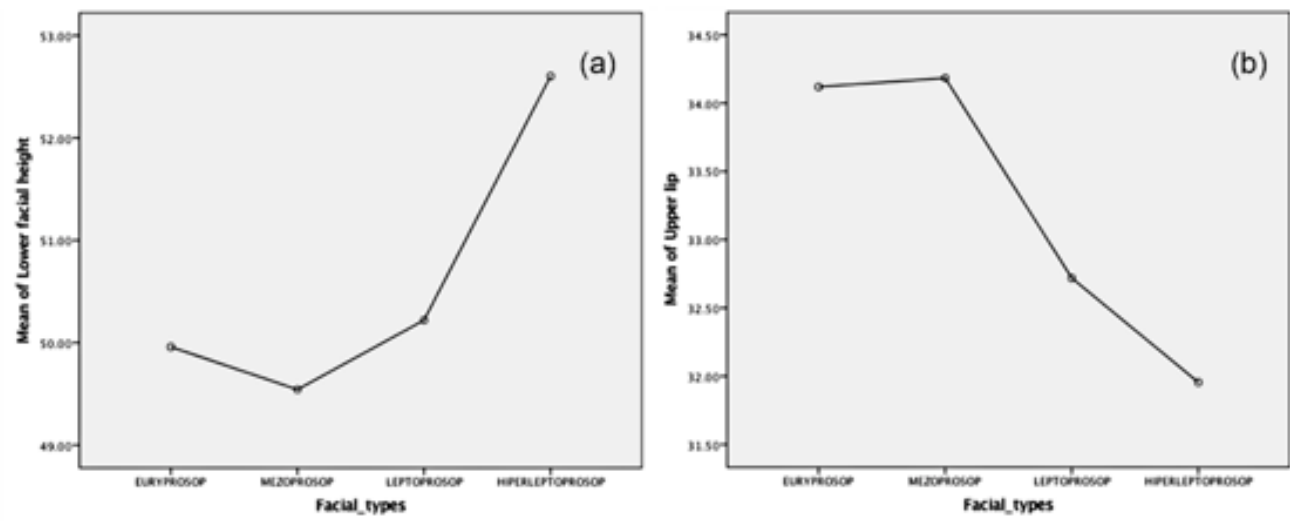

Fig. 4. (a) Association between the facial types and the mean of the lower height ratio $(p=0.002 *)$. (b)

Height of the upper lip varies significantly between all four facial types $\left(p=0.015^{*}\right)$

\begin{tabular}{|l|l|l|l|l|l|}
\hline & Euryprosop & Mesoprosop & Leptoprosop & Hyperleptoprosop & Total $^{-1}$ \\
\hline $\begin{array}{l}\text { Nasal } \\
\text { Breather }\end{array}$ & 13 & 10 & 7 & 8 & 38 \\
\hline $\begin{array}{l}\text { Oral } \\
\text { Breather }\end{array}$ & 4 & 9 & 13 & 16 & 42 \\
\hline \begin{tabular}{l} 
Total \\
\hline
\end{tabular} & 17 & 19 & 20 & 24 & 80 \\
\hline
\end{tabular}

Table 2

FACIAL TYPE FREQUENCY IN NASAL AND ORAL BREATHING PATIENTS 
adenoid type of facial characteristics are expressed $[18,24]$. Although the results are correct, the risk of bias in this conclusion rises from the fact that it doesn't take in account which of the younger and older patients are nasal or oral breathers. The development of craniofacial complex had a predominantly vertical direction for both respiratory types in the two age groups, even though the breathing impaired group showed a more significant longer face $[27,28]$. These findings may suggest that craniofacial morphology is rather a risk factor in developing oral breathing and not the otherwise. This argument sustains Ricketts theory, that the inflammation of adenoid tissue is less important, when compare to the bony contour and the occupied volume. Long faces children have narrow airway passage, so even a small inflammation may lead to an important airway obstruction, which may lead subsequently to mouth breathing in order to fulfill the organism needs of oxygen. To sustain this theory, the same results were found when analyzing the lower facial height and upper lip ratio, related to the age groups and respiratory pattern of children.

We found a significant positive correlation between the facial index and lower facial height ratio and a significant negative correlation between facial index and upper lip. These correlations do not give us the answer for the causality concept of adenoid faces. The fact that they are more likely to coexist in any given individual, can lead us to the next question: are the particularities of craniofacial morphology good predictors of breathing mode in this sample? To find this we used the progressive binary logistics test, which demonstrated that facial index is the most reliable predictor of all three variables. The chances of predicting an oral breathing child just by taking in consideration the numerical values of facial index are 67.5 $\%$.

\section{Conclusions}

Craniofacial morphology in breathing impaired children is significantly different from those in the control group. These findings do not support the hypothesis of a causal relationship between oral breathing and subsequent craniofacial vertical growth pattern, instead they suggest that long faces children are more likely to develop oral breathing in certain conditions. These conditions subsequently will have a negative effect on increasing the lower facial height, by altering the postural behavior of mandible and tongue. In other words, genetically predetermined craniofacial growth may be modulated by exogenic influences to a certain extent.

\section{References}

1. VIG, K.W.L. Nasal obstruction and facial growth: The strength of evidence for clinical assumptions. Am J Orthod Dentofacial Orthop 1998;113:603-611.

2. MOSS, M.L. The functional matrix hypothesis revisited. 4. The epigenetic antithesis and the resolving synthesis. Am J Orthod Dentofacial Orthop. 1997 Oct;112(4):410-417.

3. SUBTELNY, J,D. Oral respiration: Facial maldevelopment and corrective dentofacial orthopedics. Angle Orthod. $1980 ; 50$ (3):147164.

4. MCNAMARA, J.A. Influence of respiratory pattern on craniofacial growth. Angle Orthodontist. 1981;51(4):269-300.

5. BAUMANN PLINKERT, P.K. Effect of breathing mode and nose ventilation on growth of the facial bones, HNO. 1996 May;44(5):229234.

6. KLUEMPER, G.T., VIG, P.S., VIG, K.W. Nasorespiratory characteristics and craniofacial morphology. Eur J Orthod. 1995 Dec;17(6):491
7. MANKARIOUS, L.A., GOUDY, S.L. Craniofacial and upper airway development. Pediatric respiratory Reviews 2010; 11:193-198

8. SALEM, O.H., BRASS, B.S., ANNINO, D.J. Nasorespiratory function and craniofacial morphology-A review of the surgical management of the upper airway. Seminars in Orthodontics 2004;10:54-62.

9. GUNGOR, A.Y., TUKKAHRAMAN, H. Effects of airway problems on maxillary growth: a review. Eur J Dent 2009;3:250-254.

10. TOURNE, L.P.M. The long face syndrome and impairment of the nasopharyngeal airway. The Angle Orthodontist; 60(3):167-176.

11. LINDER-ARONSON, S. Effects of adenoidectomy on the dentition and facial skeleton over a period of 5 years, Transactions of the Third International Orthodontics Congress, London, 1975, Crosby Lockwood Stamples, pp. 85-100.

12. WEIDER, D.J ., GREG, L., BAKER, I., SALVATORIELLO, F.W. Dental malocclusion and upper airway obstruction, an otolaryngologist's perspective.Int J Pediatr Otorhinolaryngol. 2003;67:323-331.

13. KERR, W.J., MCWILLIAM, J.S., LINDER-ARONSON, S. Mandibular form and position related to changed mode of breathing--a five-year longitudinal study., Angle Orthod. 1989 Summer;59(2):91-6.

14. PELTOMAKI, T. The effect of mode of breathing on craniofacial growth- revisited. European J ournal of orthodontics 2007;29:426-429. 15. SOLOW, B., SANDHAM, A. Cranio-cervical posture: a factor in the development and function of the dentofacial structures. European J ournal of Orthodontics 2002;24:447-56.

16. SOLOW B., SONNENSEN, L. Head posture and malocclusions. European Journal of Orthodontics 1998;20:685-93.

17. SOLOW, B., SIERSBAEK-NIELSEN, S., GREVE, E. Airway adequacy, head posture, and craniofacial morphology. Am. J. Orthod. 1984;86(3):214-223.

18. CHENG, M.C., ENLOW, D.H., PAPSIDERO, M., BROADBENT, B.H., OYEN, O., SABAT, M. Development effects of impaired breathing in the face of the growing child. The Angle Orthodontist 1980;58(4):30920.

19. ROSSI, R.C., ROSSI, N.J., ROSSI, N.J.C., YAMASHITA, H.K., PIGNATARI, S.N. Dentofacial characteristics of oral breathers in different ages: a retrospective case-control study, Progress in Orthodontics (2015) 16:23

20. D'ASCANIO, L., LANCIONE, C., POMPA, G., REBUFFINI, E., MANSI, N., MANZINI, M. Craniofacial growth in children with nasal septum deviation: A cephalometric comparative study. International Journal of Pediatric Otorhinolaryngology 2010;74:1180-1183.

21. BERCEANU, C., CIUREA, E.L., CIRSTOIU, M.M., BERCEANU, S., OFITERU, A.M., MEHEDINTU, C., BERBECE, S.I., CIORTEA, R., STEPAN, A.E., BALSEANU, A.T., Rev. Chim. (Bucharest), 69, no. 9, 2018, p. 2396-2401

22. LOPATIENE, K., BABARSKAS, A. Malocclusion and upper airway obstruction. Medicina 2002;38:277-83

23. MUNOZ, I.C.L., ORTA, P.B. Comparison of cephalometric patterns in mouth breathing and nose breathing children. International J ournal of Pediatric Otorhinolaryngology 2014;78:1167-1172.

24. BERCEANU, C., PAITICI, S., BERCEANU, S., BRATILA, E., OFITERU, A.M., MEHEDINTU, C., BERBECE, S.I., NAVOLAN, D., OBLEAGA, C.V., BALSEANU, A.T., Rev. Chim. (Bucharest), 69, no. 8, 2018, p. 2245-2250 25. AGOSTIHNO, H.A., FURTADO, I.A., SILVA, F.S., TORRENT, J.U. Cephalometric evaluation of children with allergic rhinitis and mouth breathing. Acta Med Port 2015;28(3):316-321

26. BIANCHINI, A.P., GUEDES, Z.C., VIEIRA, M.M. A study on the relationship between mouth breathing and facial morphological pattern. Braz J Otorhinolaryngol. 2007 Jul-Aug;73(4):500-5.

27. BERBECE, S., ILIESCU, D., ARDELEANU, V., NICOLAU, A., JECAN, C.R. Rev. Chim. (Bucharest), 68, no. 7, 2017, p. 1438-1441

28. BOLZAN, G., SOUZA, J.A., BOTON, L.M., TONIOLO, A.M., CORRÊA, C.E.R. Facial type and head posture of nasal and mouth-breathing children J Soc Bras Fonoaudiol. 2011;23(4):315-20.

Manuscript received: 14.02 .2019 